\title{
Manejo de míldio no cultivo protegido de videira de mesa 'BRS Clara'
}

\author{
Werner Genta(1), Dauri José Tessmann(1), Sérgio Ruffo Roberto(2), João Batista Vida(1), \\ Larissa Abgariani Colombo(2), Claudia Regina Scapin ${ }^{(1)}$, Willian da Silva Ricce ${ }^{(2)}$ e Luiz Rafael Clovis ${ }^{(1)}$
}

(1)Universidade Estadual de Maringá, Departamento de Agronomia, CEP 87020-900 Maringá, PR. E-mail: werner@isuper.com.br, djtessmann@uem.br, jbvida@uem.br, claudiascapin@hotmail.com, luizrafaelclovis@hotmail.com (2)Universidade Estadual de Londrina, Departamento de Agronomia, CEP 86051-990 Londrina, PR. E-mail: sroberto@uel.br, labgariani@ig.com.br, wilianricce@gmail.com

Resumo - O objetivo deste trabalho foi avaliar a eficiência da cobertura de plástico e da tela antigranizo associadas, ou não, a programas de aplicação de fungicidas, no controle de míldio na cultivar de uva de mesa BRS Clara, sob condições de produção das safras normal e temporã do norte do Paraná, e analisar a influência de variáveis micrometeorológicas no progresso da doença. Foram conduzidos experimentos em duas safras normais (setembro a dezembro) e duas safras temporãs (janeiro a maio) nos anos 2008 e 2009. O delineamento experimental foi de blocos ao acaso, com sete tratamentos e quatro repetições: cobertura com tela antigranizo sem uso de fungicidas para controle de míldio ou com uso de fungicidas (padrão do produtor); cobertura de plástico sem uso de fungicidas ou com fungicidas apenas para oídio; cobertura de plástico com 25 ou $50 \%$ das aplicações de fungicidas padrão; e cobertura de plástico com tratamento de fosfito e cobre. A cobertura de plástico permite reduzir o número de pulverizações de fungicidas em até $75 \%$ em relação à tela antigranizo. A severidade da doença apresenta alta correlação positiva com o número de horas diárias de molhamento foliar e com a umidade relativa do ar maior que $90 \%$. Sob tela antigranizo, a severidade da doença também se correlaciona com a intensidade de chuva.

Termos para indexação: Plasmopara viticola, Vitis, manejo de doenças, microclima, plasticultura.

\section{Downy mildew management in protected cultivation of table grapes 'BRS Clara'}

\begin{abstract}
The objective of this work was to evaluate the efficiency of plastic cover and plastic shade screen, associated or not with fungicide spray programs, for downy mildew control in 'BRS Clara' table grapes in the first and second growing seasons in Northern Paraná State, and to analyze the influence of microclimatic variables on disease progress. The first and the second growing seasons assessed were from September to December and from January to May, respectively. The experiments were carriet out twice in two growing seasons - September to December, and January to May - in 2008 and 2009. The experimental design was a randomized block with seven treatments and four replicates. The following treatments were compared: plastic shade screen without fungicides for controlling downy mildew, or plastic shade with fungicides applied according to conventional standards; plastic cover without fungicide or with powdery mildew fungicides only; plastic cover with $25 \%$ or $50 \%$ of fungicides specified by conventional standards; and plastic cover with phosphite and copper fungicides. The plastic cover allows to reduce the number of fungicide applications required to control downy mildew up to $75 \%$, in comparison to the plastic shade screen. The disease severity has a high positive correlation with the duration of leaf wetness and with the air relative humidity higher than $90 \%$. Under the plastic shade screen, severity is also highly correlated with the amount of rainfall.
\end{abstract}

Index terms: Plasmopara viticola, Vitis, disease management, microclimate, plasticulture.

\section{Introdução}

A cultivar BRS Clara (Vitis sp.), oriunda do cruzamento entre a linhagem CNPUV 154-147 e a cultivar Centennial Seedless, é uma nova alternativa de uva de mesa apirênica para regiões tropicais e subtropicais do Brasil (Camargo et al., 2003). No entanto, assim como as uvas de mesa originadas de V. vinifera L., essa cultivar apresenta susceptibilidade ao míldio, causada pelo fungo biotrófico Plasmopara viticola (Berk. \& Curtis) Berrl. \& de Toni. O míldio danifica folhas, ramos herbáceos, inflorescências e bagas da videira, e pode levar à perda total da produção (Naves et al., 2005).

No norte do Paraná, a produção de uva de mesa é realizada com dupla poda anual, o que permite duas safras em um ano. Na safra normal, a poda é realizada no inverno, no final do repouso hibernal, nos meses

Pesq. agropec. bras., Brasília, v.45, n.12, p.1388-1395, dez. 2010 
de julho e agosto, com a realização da colheita em dezembro e janeiro. Na safra temporã, a poda ocorre no verão, imediatamente após a colheita da safra originada pela poda de inverno, com realização da colheita entre maio e junho. No entanto, esse sistema de produção intensivo é afetado pelo míldio, cujo elevado potencial de danos em condições meteorológicas de elevada precipitação pluvial aumenta a percepção de risco de perdas por parte dos produtores, impelindo-os a fazer aplicações de fungicidas. Por sua vez, a proteção da parreira com tela antigranizo, comum na região, não previne o molhamento da parte aérea da parreira pela água da chuva ou orvalho e, assim, não diminui a intensidade de míldio e demais doenças que são dependentes de umidade, como antracnose [Elsinoe ampelina (de Bary) Shear], podridão-da-uva-madura [Glomerella cingulatta (Stonem.) Spauld. et Schernk], podridão-cinzenta-da-uva [Botryotinia fuckeliana (de Bary) Whetzel] e podridão-ácida (leveduras) (Naves et al., 2005).

A ocorrência de epidemias de míldio está condicionada à presença de umidade na parte aérea da parreira e tanto mais severas são as epidemias quanto mais frequentes e prolongados forem os períodos de molhamento dos tecidos verdes da planta. A ocorrência simultânea de chuvas e ventos contribui sobremaneira para a disseminação da doença no interior do parreiral. Períodos prolongados de molhamento foliar são fundamentais nesse patossistema porque os processos de infecção e esporulação de $P$. viticola são dependentes de água livre (Lafon \& Clerjeau, 1988).

Diversos trabalhos mostram que a cobertura de plástico sobre as fileiras de plantas resulta em alterações no microclima das parreiras (Lulu et al., 2005; Chavarria et al., 2007; Cardoso et al., 2008; Novello \& Palma, 2008; Chavarria \& Santos, 2009). O emprego desse tipo de procedimento é uma alternativa válida para a minimização do molhamento da parte aérea da videira causado pela chuva, e pode reduzir a ocorrência de doenças. Um estudo realizado no estado de São Paulo com a cultivar Romana (A 1105) mostrou que o uso de cobertura de plástico reduziu a incidência de podridões no cacho e contribuiu para a melhoria da qualidade dos frutos (Lulu et al., 2005). No Rio Grande do Sul, Chavarria et al. (2007) constataram na cultivar Moscato Giallo, que o uso de cobertura de plástico reduziu a intensidade de podridão-da-uva-madura, podridão-cinzenta-da-uva e podridão-ácida, com substancial redução do uso de agrotóxicos. Verificouse também que a cobertura de plástico possibilita aumento na produtividade e favorece a estabilidade da produção da parreira (Chavarria et al., 2009).

Os objetivos deste trabalho foram avaliar a eficiência da cobertura de plástico e da tela antigranizo, associadas ou não a programas de aplicação de fungicidas, no controle de míldio na cultivar de uva de mesa BRS Clara, sob condições de produção das safras normal e temporã do norte do Paraná, e analisar a influência de variáveis meteorológicas no progresso da doença.

\section{Material e Métodos}

Os experimentos foram conduzidos em dois parreirais de uva de mesa apirênica da cv. BRS Clara (Vitis sp.) - cruzamento entre 'CNPUV 154-147' x 'Centennial Seedless' -, localizados lado a lado, com quatro anos de idade, conduzido em sistema latada, no

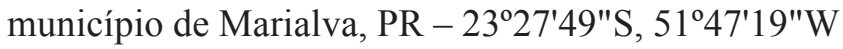
e altitude de $618 \mathrm{~m}$-, no período de 2007 a 2009.

No local de realização dos experimentos, segundo a classificação de Köppen, ocorre o tipo climático Cfa. A temperatura média do mês mais frio é inferior a $18^{\circ} \mathrm{C}$ e a do mês mais quente é superior a $22^{\circ} \mathrm{C}$, o que caracteriza um clima mesotérmico com verão quente e inverno ameno. As videiras foram cultivadas no espaçamento de $4 \mathrm{~m}$ entre plantas e $3 \mathrm{~m}$ entre linhas, com apenas um cordão principal no sentido da linha. O tamanho da parcela experimental foi de $24 \mathrm{~m}^{2}$, sendo considerada útil a área central da parcela com $12 \mathrm{~m}^{2}$. A parcela foi constituída por uma planta inteira (parcela útil) e por duas metades de plantas vizinhas.

Dois experimentos foram conduzidos por quatro safras. O primeiro experimento foi implantado em parreiral formado por plantas de videira 'BRS Clara' enxertada sobre o porta-enxerto IAC-572 'Jales'. O segundo experimento foi implantado em parreiral constituído por 'BRS Clara' enxertada sobre o porta-enxerto IAC-766 'Campinas'. Nos experimentos das safras normais, os ramos foram podados em $4 / 9 / 2007$ e 28/8/2008, e os frutos colhidos em $19 / 12 / 2007$ e 18/12/2008, respectivamente. Nas safras temporãs, os ramos foram podados em 28/1/2008 e 16/1/2009, e os frutos colhidos em 23/5/2008 e $7 / 5 / 2009$, respectivamente. A brotação dos ramos foi estimulada quimicamente com cianamida hidrogenada 
a $4 \%$. Foram selecionados um a dois brotos por ramo podado, de modo a manter entre 50 e 60 brotos por planta. O desponte foi feito quando os ramos atingiram de 16 a 20 folhas, com o propósito de direcionar os nutrientes para os cachos e controlar a área foliar no parreiral. A colheita foi realizada em uma única data, quando os cachos apresentaram teor de sólidos solúveis superior a $18^{\circ}$ Brix.

Utilizou-se o delineamento experimental de blocos ao acaso, com sete tratamentos e quatro repetições. Foram comparados os seguintes tratamentos: 1, cobertura com tela de proteção antigranizo sem fungicidas; 2, tela de proteção antigranizo com fungicidas, que recebeu um programa de fungicidas considerado padrão pelos produtores da região (Tabela 1); 3, cobertura com plástico e aplicação de fungicidas para oídio; 4 , plástico com $50 \%$ de redução do programa de fungicidas padrão; 5 , plástico com $75 \%$ de redução em relação ao programa de fungicidas padrão; e 6, plástico com fosfito e cobre, que recebeu aplicações preventivas de fosfito de potássio e hidróxido de cobre para míldio; e 7, plástico sem fungicidas. Na cobertura com plástico, as fileiras de plantas foram cobertas com lona de plástico rafiada com $150 \mu \mathrm{m}$ de espessura, aditivada contra raios ultravioleta (Procópio Indústria e Comércio, Campo Largo, PR). Essa lona

Tabela 1. Ingredientes ativos dos fungicidas utilizados nos tratamentos.

\begin{tabular}{lcc}
\hline Tratamento & Ingrediente ativo & Dose $\left(\mathrm{g} 100 \mathrm{~L}^{-1}\right)$ \\
\hline & Piraclostrobina + Metiram & $110+10$ \\
& Cimoxanil + Mancozeb & $20+160$ \\
& Cimoxanil + Famoxadona & $18+13,5$ \\
& Metalaxil + Mancozeb & $10+160$ \\
& Iprovalicarbe + Propinebe & $13,7+153,3$ \\
Programa de fungicidas & Fenamidone & 15 \\
calendarizado padrão & Famoxadona + Mancozeb & $12,5+125$ \\
utilizado pelos produtores & Mancozeb & 240 \\
& Hidróxido de cobre & 96,8 \\
& Difenoconazole & 3 \\
& Tiofanato metílico & 49 \\
& Fenarimol & 2,4 \\
Fungicidas para controle & Captan & 120 \\
de oídio utilizados no & Difenoconazole & 3 \\
tratamento 3 & Tiofanato metílico & 49 \\
\hline & Fenarimol & 2,4 \\
\hline Fungicidas utilizados no & Fosfito de potássio & $300^{(1)}$ \\
tratamento 6 & Hidróxido de cobre & 96,8 \\
& Difenoconazole & 3 \\
& Tiofanato metílico & 49 \\
\hline
\end{tabular}

(1) Produto formulado a base de $40 \%$ de $\mathrm{P}_{2} \mathrm{O}_{5}+20 \%$ de $\mathrm{K}_{2} \mathrm{O}$. foi fixada em um arco de cano galvanizado com $2 \mathrm{~m}$ de largura, diâmetro de $1 / 2$ polegada e cumeeira com altura de $0,6 \mathrm{~m}$ acima do dossel da parreira.

$\mathrm{Na}$ cobertura com tela antigranizo, as plantas foram cobertas com tela de polietileno de alta densidade, o que proporcionou $18 \%$ de sombreamento. Essa tela foi instalada na altura de $0,6 \mathrm{~m}$ acima do dossel da parreira. Os tratamentos 2 a 6 receberam pulverizações preventivas de fungicidas para o controle de oídio [Uncinula necator (Schw.) Burr.], a fim de evitar a interferência dessa doença. No programa de fungicidas padrão, foram realizadas de três a cinco pulverizações de fungicidas a cada sete dias, no período entre a primeira e a oitava semana após o início da brotação dos ramos, e uma a duas pulverizações a cada sete dias entre a nona e a décima segunda semana, no total de 42, 38, 45 e 71 pulverizações na safra normal de 2007, safra temporã de 2008, safra normal de 2008 e safra temporã de 2009, respectivamente. No tratamento 3 , apenas fungicidas foram utilizados para controle de oídio, com pulverizações preventivas no período entre a quinta e a décima segunda semana após o início da brotação dos ramos, totalizando 6, 8, 9 e 12 pulverizações para a safra normal de 2007, safra temporã de 2008, safra normal de 2008 e safra temporã de 2009, respectivamente. No tratamento 6, foram realizadas entre uma a três pulverizações a cada sete dias no período entre a primeira e a décima segunda semana após o início da brotação dos ramos, num total de $11,28,13$ e 32 pulverizações para a safra normal de 2007, safra temporã de 2008, safra normal de 2008 e safra temporã de 2009, respectivamente. Nas primeiras quatro semanas após o início da brotação dos ramos, o volume da calda foi de $400 \mathrm{~L} \mathrm{ha}^{-1}$ e, nas semanas seguintes, o volume da calda foi de $800 \mathrm{~L} \mathrm{ha}^{-1}$.

Para a avaliação da doença, foram marcados quatro ramos na área útil da parcela, cada ramo contendo um cacho. Nas folhas, a severidade da doença, identificada pela percentagem de área foliar doente, foi avaliada a cada sete a dez dias, utilizando-se a escala descritiva de Horsfall-Barratt reproduzida em Campbell \& Madden (1990). Com base nesses dados, foram determinadas a área abaixo da curva de progresso da severidade do míldio (AACPS) e as curvas de progresso da doença em função do tempo. Nos cachos, foi realizada apenas uma avaliação de incidência na fase de maturação dos frutos. Avaliaram-se dez cachos por parcela, considerando-se doente o cacho que apresentou mais de 5\% das 
bagas com sintomas de míldio e os resultados foram expressos em percentagem de incidência de míldio nos cachos (IMC). Na avaliação da produtividade, os cachos da parcela útil foram colhidos, pesados e os dados transformados em $\mathrm{kg} \mathrm{ha}^{-1}$.

Os dados foram submetidos à análise de variância para efeitos de tratamentos (sete), épocas de cultivo (quatro safras) e porta-enxertos (dois), e das interações tratamento $\mathrm{x}$ época, tratamento $\mathrm{x}$ porta-enxerto, época $\mathrm{x}$ porta-enxerto e tratamento $\mathrm{x}$ época $\mathrm{x}$ porta-enxerto. As médias foram comparadas pelo teste Scott-Knott, a $5 \%$ de probabilidade, utilizando-se o SISVAR 4.2 (Ferreira, 2008).

Dados micrometeorológicos de temperatura, umidade relativa do ar, duração do molhamento foliar, precipitação pluvial e velocidade do vento foram coletados sob cobertura de plástico e sob tela antigranizo. Nesse procedimento, foram utilizadas estações meteorológicas automáticas $\mu$ METOS, modelo MCR200, (Pessl Instruments, Weiz, Áustria) com sensores localizados próximo ao dossel vegetativo, nos tratamentos 1 e 7 do parreiral de 'BRS Clara' enxertada sobre o porta-enxerto IAC-572 'Jales'. Como a esporulação do míldio é favorecida pelo molhamento foliar sem a presença de luz (Lafon \& Clerjeau, 1988), os dias foram considerados como tendo início às $12 \mathrm{~h}$ e término às $11 \mathrm{~h} 59 \mathrm{~min}$ do dia seguinte, de modo a não dividir o período noturno. Nas análises de correlação linear entre o progresso da doença e as variáveis micrometeorológicas, foram consideradas as médias ou os valores acumulados das variáveis meteorológicas no período de sete dias anteriores a cada data de avaliação da severidade da doença. A análise de correlação entre o desenvolvimento da doença e variáveis meteorológicas foi feita por meio do programa SAS (SAS Institute, 2001).

\section{Resultados e Discussão}

Ocorreram epidemias de míldio na safra normal de 2008 e nas safras temporãs de 2008 e 2009 , porém não ocorreu epidemia de míldio na safa normal de 2007 (Tabela 2). A ausência da doença na safra normal de 2007 é atribuída à menor quantidade de chuva e menor número de horas diárias com molhamento foliar em relação às demais safras (Tabela 3 ). A chuva favorece o progresso de míldio porque, além de proporcionar umidade aos tecidos da planta, o que favorece a esporulação do patógeno e infecção, promove a dispersão do inóculo do patógeno no parreiral (Lafon \& Clerjeau, 1988).

$\mathrm{Na}$ safra normal de 2008, os tratamentos que proporcionaram menor AACPS nas folhas foram plástico com $50 \%$ de redução do padrão, plástico com $75 \%$ de redução do padrão, plástico com fosfito e cobre e tela antigranizo com fungicida (padrão) (Tabela 2). No entanto, em relação à IMC, esses tratamentos não diferiram dos tratamentos que consistiram na utilização de plástico sem fungicidas para míldio e plástico sem fungicidas. Na safra temporã de 2008, os tratamentos que proporcionaram menores AACPS e IMC foram plástico com $50 \%$ de redução do padrão e plástico com $75 \%$ de redução do padrão. Deve-se acrescentar que esses dois tratamentos proporcionaram maior

Tabela 2. Média da área abaixo da curva de progresso da severidade do míldio (AACPS) nas folhas e da incidência de míldio nos cachos (IMC) de videira cultivar BRS Clara sobre os porta enxertos IAC-572 'Jales' e IAC-766 'Campinas', nas safras normal (setembro a dezembro) e temporã (janeiro a maio) $)^{(1)}$.

\begin{tabular}{|c|c|c|c|c|c|c|}
\hline \multirow[t]{2}{*}{ Tratamento } & \multicolumn{2}{|c|}{ Safra normal 2008} & \multicolumn{2}{|c|}{ Safra temporã 2008} & \multicolumn{2}{|c|}{ Safra temporã 2009} \\
\hline & AACPS & $\operatorname{IMC}(\%)^{(2)}$ & AACPS & IMC (\%) & AACPS & IMC (\%) \\
\hline Tela antigranizo sem fungicida & $1.775 \mathrm{a}$ & $100 \mathrm{a}$ & $6.945 \mathrm{a}$ & $100 \mathrm{a}$ & $6.564 a$ & $100 \mathrm{a}$ \\
\hline Tela antigranizo com fungicidas (padrão) & $12 \mathrm{c}$ & $16 b$ & $58 \mathrm{~d}$ & $59 b$ & $53 \mathrm{c}$ & $0 \mathrm{~d}$ \\
\hline Plástico sem fungicida para míldio & $232 b$ & $3 b$ & $1.121 \mathrm{c}$ & $100 \mathrm{a}$ & $2.705 \mathrm{~b}$ & $100 \mathrm{a}$ \\
\hline Plástico com $50 \%$ de redução do padrão & $2 \mathrm{c}$ & $0 \mathrm{~b}$ & $10 \mathrm{e}$ & $0 \mathrm{c}$ & $96 c$ & $28 \mathrm{c}$ \\
\hline Plástico com $75 \%$ de redução do padrão & $1 \mathrm{c}$ & $3 b$ & $6 e$ & $6 \mathrm{c}$ & $72 \mathrm{c}$ & $25 \mathrm{c}$ \\
\hline Plástico com fosfito e cobre & $10 \mathrm{c}$ & $0 \mathrm{~b}$ & $136 \mathrm{~d}$ & $69 b$ & $110 \mathrm{c}$ & $63 b$ \\
\hline Plástico sem fungicida & $171 b$ & $9 \mathrm{~b}$ & $1.894 \mathrm{~b}$ & $100 \mathrm{a}$ & $2.858 \mathrm{~b}$ & $100 \mathrm{a}$ \\
\hline $\mathrm{CV}(\%)$ & 23,0 & 27,9 & 21,1 & 27,4 & 23,9 & 34,2 \\
\hline
\end{tabular}

${ }^{(1)}$ Médias seguidas de letras iguais, nas colunas, não diferem entre si pelo teste Scott-Knott, a 5\% de probabilidade. Dados transformados para $\mathrm{x}^{0,5}$. (2)Percentagem de cachos com míldio, média de quatro repetições. 
redução da doença do que o tratamento padrão. Nessa safra o padrão não diferiu do tratamento que utilizou plástico com fosfito e cobre. Na safra temporã de 2009, o tratamento padrão, e os tratamentos que utilizaram plástico com $50 \%$ de redução do padrão, plástico com $75 \%$ de redução do padrão, plástico com fosfito e cobre proporcionaram menores valores de AACPS.

Nos cachos, o melhor tratamento foi o padrão, seguido por plástico com $50 \%$ de redução do padrão e plástico com $75 \%$ de redução do padrão. Esses resultados mostram que a cobertura de plástico sobre as fileiras de plantas é uma medida válida para a redução da severidade do míldio da videira no norte do Paraná. Porém, o efeito da cobertura de plástico na redução da doença verificado neste trabalho não parece estar relacionado unicamente com a diminuição do molhamento foliar, uma vez que somente na safra normal de 2007 ocorreu redução drástica no número de horas diárias com molhamento foliar sob a cobertura de plástico em relação à tela antigranizo (Tabela 3). Nas demais safras, quando a quantidade de chuva foi maior, não ocorreu redução drástica do número de horas diárias com molhamento foliar sob a cobertura de plástico em relação à tela antigranizo. Isso pode ser atribuído ao fato de a cobertura de plástico não evitar a ocorrência de respingos de chuva decorrentes de chuvas associadas a ventos fortes, comuns no verão, e também à menor aeração no dossel vegetativo sob o plástico. Assim, a restrição de água livre sobre as folhas e frutos, como aventado por Chavarria \& Santos (2009), não foi o fator preponderante para a redução da doença sob o plástico. Dessa forma, outros fatores também podem estar envolvidos na redução da doença sob o plástico, como o maior efeito residual dos fungicidas em decorrência da menor degradação ou remoção pela chuva, porém essa hipótese deve ser investigada em trabalhos futuros.

Outros estudos com cobertura de plástico não constataram incidência de míldio durante a condução dos experimentos, provavelmente pela diferença de sistemas de condução adotados. O presente trabalho foi realizado com uma cultivar de mesa no sistema de produção latada, com dupla poda anual, enquanto o estudo de Chavarria et al. (2007) foi realizado na Serra Gaúcha com a uva vinífera cultivar Moscato Giallo, cultivada sob sistema em Y, tendo sido verificado apenas podridões do cacho. Também no estudo realizado por Lulu et al. (2005), com a cultivar de mesa romana, na região de Jundiaí, SP, não há relatos sobre dano por míldio.

A análise de variância para as variáveis AACPS e IMC também mostrou significância $(p \leq 0,05)$ para os efeitos da época de cultivo e interação tratamento x época de cultivo. No entanto, essa interação foi significativa apenas nos tratamentos com tela antigranizo sem fungicida, plástico sem fungicida para míldio e plástico sem fungicida, os quais não utilizaram fungicidas para controle de míldio. Com relação ao efeito da época de cultivo ou safra, as diferenças de intensidade de míldio entre as duas safras temporãs não foram significativas, porém as diferenças de intensidade entre as safras temporãs e as safras normais, bem como entre as duas safras normais, foram significativas. Os efeitos de porta-enxerto e das interações entre porta-enxertos com tratamentos e época de cultivo não foram significativos.

Tabela 3. Valores médios ou acumulados das observações micrometeorológicas em parreiral da cultivar BRS Clara enxertada sobre o porta enxerto IAC-572 'Jales', com cobertura de plástico e cobertura com tela anti-granizo ambos sem aplicação de fungicidas nos primeiros 75 dias após a poda dos ramos.

\begin{tabular}{|c|c|c|c|c|c|c|c|c|}
\hline \multirow[t]{2}{*}{ Variável micrometeorológica $^{(1)}$} & \multicolumn{2}{|c|}{ Safra normal $2007^{(2)}$} & \multicolumn{2}{|c|}{ Safra normal $2008^{(3)}$} & \multicolumn{2}{|c|}{ Safra temporã $2008^{(4)}$} & \multicolumn{2}{|c|}{ Safra temporã $2009^{(5)}$} \\
\hline & Plástico & Tela & Plástico & Tela & Plástico & Tela & Plástico & Tela \\
\hline Tméd $\left({ }^{\circ} \mathrm{C}\right)$ & 23,1 & 23,1 & 21,1 & 20,9 & 22,8 & 22,8 & 24 & 23,7 \\
\hline Tmín $\left({ }^{\circ} \mathrm{C}\right)$ & 18,1 & 18,1 & 15,9 & 16,1 & 18,2 & 18,4 & 19,4 & 19,6 \\
\hline Tmáx $\left({ }^{\circ} \mathrm{C}\right)$ & 30,6 & 30,3 & 28,7 & 27,8 & 29,9 & 29,3 & 31,1 & 30,0 \\
\hline HURA $>90 \%$ (horas) & 3,6 & 7,2 & 3,6 & 3,6 & 9,9 & 14,9 & 3,6 & 7,2 \\
\hline MF (horas) & 0,3 & 3,7 & 4,0 & 4,9 & 4,9 & 5,5 & 5,9 & 7,1 \\
\hline Chuva (mm) & 0,0 & 5,4 & -(6) & 418,4 & - & 471,8 & - & 719,0 \\
\hline
\end{tabular}

(1)Tméd, Tmín e Tmáx, médias diárias de temperatura do ar média, mínima e máxima, respectivamente; HURA>90\% e MF, médias diárias de horas com umidade relativa maior que $90 \%$ e de horas com molhamento foliar, respectivamente. ${ }^{(2)} 4 / 9 / 2007$ a 18/11/2007. ${ }^{(3)} 28 / 1 / 2008$ a 12/4/2008. ${ }^{(4)} 28 / 8 / 2008$ a 11/11/2008. ${ }^{(5)} 16 / 1 / 2009$ a 1/4/2009. (6) Não determinado. 
O manejo convencional de míldio exclusivamente com cobertura de plástico com associação de fosfito de potássio e fungicida cúprico não apresentou a mesma eficiência em relação à AACPS e ao IMC do que o tratamento padrão na safra temporã de 2008, e também foi menos eficiente do que os tratamentos com plástico com redução de $50 \%$ ou $75 \%$ do padrão (Tabela 2). O mesmo foi verificado na safra temporã de 2009 em relação ao IMC. Essa variação na eficiência do tratamento com cobertura de plástico associada a fosfito de potássio e cobre é atribuída à influência do clima mais úmido registrado nas safras temporãs (Tabela 3). Czermainski \& Sônego (2004) também

Tabela 4. Produtividade média $\left(\mathrm{Mg} \mathrm{ha}^{-1}\right)$ de videira cultivar BRS Clara sobre os porta enxertos IAC-572 'Jales' e IAC-766 'Campinas' nas safras normal (setembro a dezembro) e temporã (janeiro a maio) ${ }^{(1)}$.

\begin{tabular}{lcccrr}
\hline Tratamentos & \multicolumn{2}{c}{ Safra normal } & \multicolumn{2}{c}{ Safra temporã } \\
\cline { 2 - 3 } \cline { 6 - 6 } & 2007 & 2008 & & 2008 & 2009 \\
\hline Tela antigranizo sem fungicida & 12,0 & $-(2)$ & & - & - \\
Tela antigranizo com fungicidas (padrão) & 9,2 & $18,9 \mathrm{a}$ & & $21,8 \mathrm{a}$ & $39,9 \mathrm{a}$ \\
Plástico sem fungicida para míldio & 10,4 & $19,1 \mathrm{a}$ & $1,8 \mathrm{c}$ & $3,7 \mathrm{~b}$ \\
Plástico com 50\% de redução do padrão & 9,5 & $23,1 \mathrm{a}$ & $18,9 \mathrm{a}$ & $32,4 \mathrm{a}$ \\
Plástico com 75\% de redução do padrão & 9,1 & $19,3 \mathrm{a}$ & $20,1 \mathrm{a}$ & $31,7 \mathrm{a}$ \\
Plástico com fosfito e cobre & 8,8 & $21,9 \mathrm{a}$ & $10,6 \mathrm{~b}$ & $10,8 \mathrm{~b}$ \\
Plástico sem fungicida & 10,4 & $15,7 \mathrm{~b}$ & $1,5 \mathrm{c}$ & $1,1 \mathrm{c}$ \\
\hline CV (\%) & 28,2 & 25,6 & 21,8 & 33,8 \\
\hline
\end{tabular}

${ }^{(1)}$ Médias seguidas de letra iguais, na coluna, não diferem entre si pelo teste Scott-Knott, a $5 \%$ de probabilidade. ${ }^{(2)}$ Não houve produção devido aos danos de míldio. verificaram que a eficiência de tratamentos fungicidas sofre a influência da ocorrência de chuva e umidade, e que fungicidas cúpricos apresentam baixa eficiência quando da ocorrência de elevada umidade durante o ciclo de cultivo da videira. A eficiência do uso de fosfito de potássio e fungicidas cúpricos no controle da doença, verificada por Peruch et al. (2007), Peruch \& Dalla Bruna (2008) e Pereira et al. (2010) pode ser atribuída à menor pressão da doença registrada naqueles trabalhos em relação a este estudo.

A produtividade não foi afetada pela doença na safra normal de 2007, porém foi afetada nas demais safras, nas quais não houve produção no tratamento que utilizou tela antigranizo sem fungicida (Tabela 4). Também em relação à produtividade, verificou-se efeito significativo da interação tratamento $\mathrm{x}$ época de cultivo $(p \leq 0,05)$, quando os tratamentos menos eficientes nas safras temporãs foram os que utilizaram plástico sem fungicida para míldio e plástico sem fungicida.

Nos tratamentos com cobertura de plástico ou tela antigranizo, verificou-se alta correlação positiva da severidade da doença com o número de horas com umidade relativa do ar maior que $90 \%$, o número de dias com quatro ou mais horas de umidade relativa do ar maior que $90 \%$, o número de horas diárias com molhamento foliar e o número de dias com quatro ou mais horas diárias com molhamento foliar (Tabela 5). No cultivo sob tela antigranizo, a severidade da doença também se correlacionou com a ocorrência de chuva. As correlações entre a severidade da doença

Tabela 5. Coeficientes de correlação linear de Pearson entre a severidade de míldio na videira cultivar BRS Clara enxertada sobre o porta-enxerto IAC 572 'Jales' e variáveis micrometeorológicas determinadas sob cobertura de plástico e tela de proteção antigranizo.

\begin{tabular}{|c|c|c|c|c|c|c|}
\hline \multirow[t]{2}{*}{ Variável micrometeorológica ${ }^{(1)}$} & \multicolumn{2}{|c|}{ Safra normal 2008} & \multicolumn{2}{|c|}{ Safra temporã 2008} & \multicolumn{2}{|c|}{ Safra temporã 2009} \\
\hline & Plástico & Tela & Plástico & Tela & Plástico & Tela \\
\hline Tmín $\left({ }^{\circ} \mathrm{C}\right)$ & $-0,647^{*}$ & $-0,640^{*}$ & $-0,770^{*}$ & $-0,552^{\mathrm{ns}}$ & $-0,512^{\mathrm{ns}}$ & $-0,463^{\text {ns }}$ \\
\hline Tmáx $\left({ }^{\circ} \mathrm{C}\right)$ & $-0,641^{*}$ & $-0,562^{\text {ns }}$ & $-0,352^{\text {ns }}$ & $-0,465^{\mathrm{ns}}$ & $-0,372^{\mathrm{ns}}$ & $-0,205^{\text {ns }}$ \\
\hline Tméd $\left({ }^{\circ} \mathrm{C}\right)$ & $-0,758^{*}$ & $-0,634^{*}$ & $-0,424^{\text {ns }}$ & $-0,386^{\text {ns }}$ & $-0,554^{\mathrm{ns}}$ & $-0,602^{*}$ \\
\hline HURA>90\% (horas) & $0,946^{*}$ & $0,936^{*}$ & $0,961 *$ & $0,937 *$ & $0,821 *$ & $0,943 *$ \\
\hline D4HURA>90\% (horas) & $0,921 *$ & $0,966^{*}$ & $0,994 *$ & $0,869 *$ & $0,908 *$ & $0,911 *$ \\
\hline HMF (horas) & $0,957^{*}$ & $0,899 *$ & $0,950^{*}$ & $0,968 *$ & $0,805^{*}$ & $0,941 *$ \\
\hline D4MF (dias) & $0,970^{*}$ & $0,966^{*}$ & $0,971 *$ & $0,875^{*}$ & $0,907 *$ & $0,940 *$ \\
\hline Chuva (mm) & $-(2)$ & $0,887^{*}$ & - & $0,985^{*}$ & - & $0,945^{*}$ \\
\hline Velocidade do vento $\left(\mathrm{km} \mathrm{h}^{-1}\right)$ & $-0,412^{\mathrm{ns}}$ & $-0,550^{\mathrm{ns}}$ & $-0,135^{\text {ns }}$ & $-0,906^{*}$ & $-0,368^{\text {ns }}$ & $0,942 *$ \\
\hline
\end{tabular}

${ }^{n s}$ Não significativo. *Significativo a $5 \%$ de probabilidade. ${ }^{(1)}$ Tméd, Tmín e Tmáx, média diária de temperatura do ar média, mínima e máxima, respectivamente; HURA $>90 \%$, média diária de horas com umidade relativa do ar maior que $90 \%$; D4HURA $>90 \%$, número de dias com quatro ou mais horas de umidade relativa do ar maior que 90\%; HMF, média diária de horas com molhamento foliar; D4HMF, número de dias com a ocorrência de quatro ou mais horas de molhamento foliar; Velocidade do vento, média diária de velocidade do vento. ${ }^{(2)}$ Não determinado. 
com temperatura e velocidade do vento não foram estatisticamente significativas em todas as safras. Esses resultados mostram que no norte do Paraná o progresso do míldio da videira apresenta maior correlação com umidade do que temperatura. Presumese que isso ocorre porque a temperatura varia menos nessa região do que nas regiões de clima mais frio, nas quais a temperatura tem um papel mais importante na epidemiologia da doença (Lafon \& Clerjeau, 1988).

A análise das curvas de progresso de míldio, nas folhas das plantas das parcelas dos tratamentos com tela antigranizo sem fungicida e plástico sem fungicida, mostra que a doença ocorreu mais cedo nas safras temporãs, nas quais os níveis máximos de severidade ocorreram anteriormente ao início da maturação dos frutos (Figuras $1 \mathrm{~A}$ e C). Na safra convencional de 2008, a doença foi constatada mais tarde, somente após o florescimento, e os níveis máximos de severidade foram registrados após o início da maturação dos frutos (Figuras 1 B e D). Esses resultados corroboram a informação de que danos causados pela doença aumentam à medida que a doença ocorre mais cedo no ciclo de produção da cultura (Lafon \& Clerjeau, 1988).
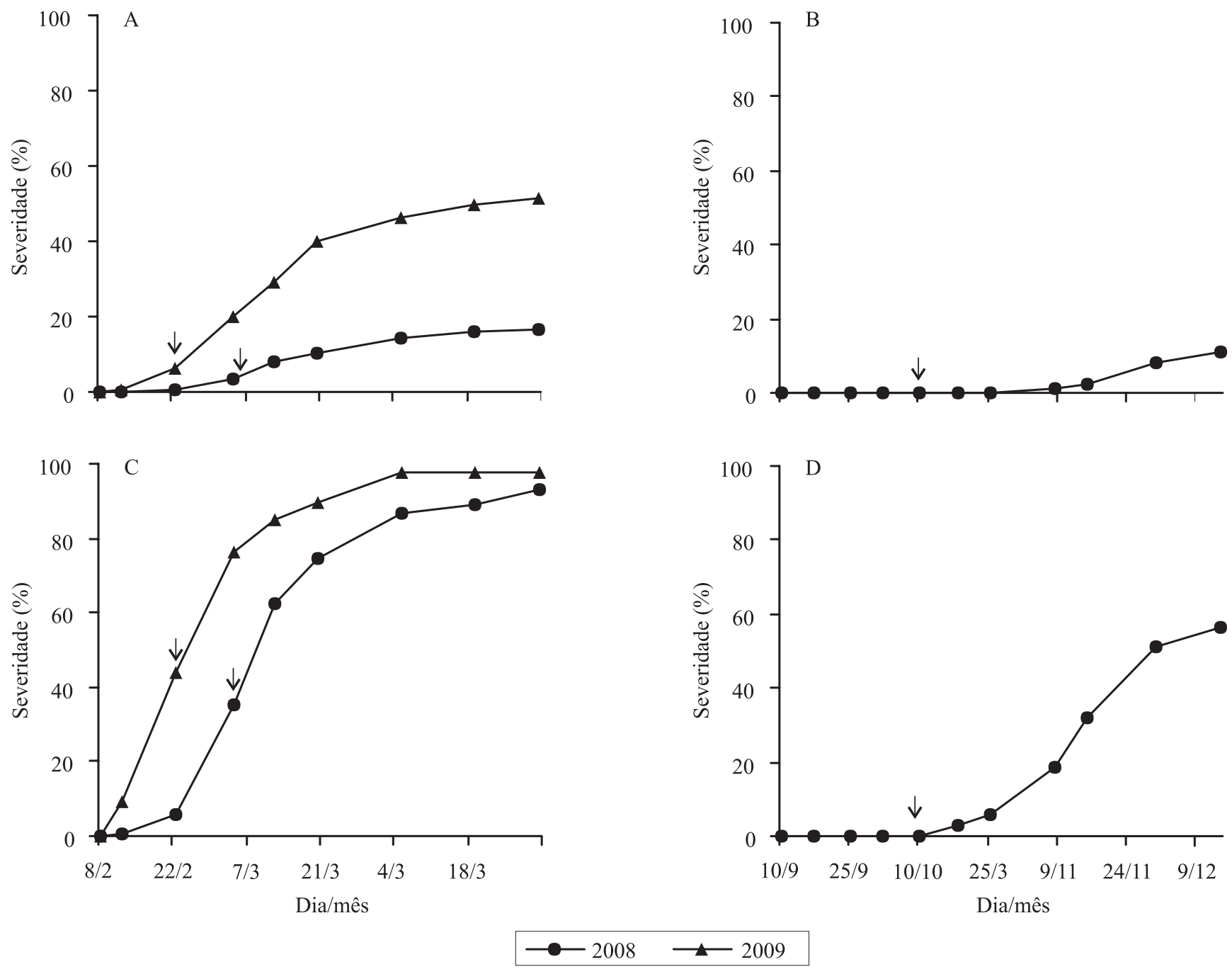

Figura 1. Curvas de progresso de míldio em videira cultivar BRS Clara cultivada sob cobertura de plástico (A e B) e sob tela antigranizo (C e D) nas safras temporãs de 2008 e 2009 (A e C) e safra normal de 2008 (B e D). A seta indica o estádio fenológico de floração plena. 


\section{Conclusões}

1. O míldio causa mais danos na safra de janeiro a maio (temporã) do que na safra de agosto a dezembro (safra normal), independentemente do sistema de cobertura utilizado.

2. A cobertura de plástico reduz a severidade de míldio em comparação com a tela antigranizo e permite reduzir o número de pulverizações de fungicidas em até $75 \%$ em relação à tela antigranizo no controle de míldio.

3. No cultivo sob tela, a doença também se correlaciona positivamente com a intensidade de chuva.

4. A severidade da doença nos dois sistemas de cultivo protegido apresenta alta correlação positiva com o número de horas diárias com umidade relativa do ar maior que $90 \%$ e duração do molhamento foliar diário.

\section{Agradecimentos}

Ao Conselho Nacional de Desenvolvimento Científico e Tecnológico, pelo suporte financeiro; aos pesquisadores, Henrique Pessoa dos Santos, Lucas da Ressurreição Garrido, Marcos Botton e Reginaldo Teodoro de Souza, da Embrapa Uva e Vinho, pelo apoio técnico.

\section{Referências}

CAMARGO, U.A.; NACHTIGAL, J.C.; MAIA, J.D.G.; OLIVEIRA, P.R.D. de; PROTAS, J.F. da S. BRS Clara: nova cultivar de uva branca de mesa sem semente. Bento Gonçalves: Embrapa Uva e Vinho, 2003. 4p. (Embrapa Uva e Vinho. Comunicado técnico, 46).

CAMPBELL, C.L.; MADDEN, L.V. Introduction to plant disease epidemiology. Nova Iorque: J. Wiley, 1990. 532p.

CARDOSO, L.S.; BERGAMASCHI, H.; COMIRAN, F.; CHAVARRIA, G.; MARODIN, G.A.B.; DALMAGO, G.A.; SANTOS, H.P. dos; MANDELLI, F. Alterações micrometeorológicas em vinhedos pelo uso de coberturas de plástico. Pesquisa Agropecuária Brasileira, v.43, p.441-447, 2008.
CHAVARRIA, G.; SANTOS, H.P. dos. Manejo de videiras sob cultivo protegido. Ciência Rural, v.39, p.1917-1924, 2009.

CHAVARRIA, G.; SANTOS, H.P. dos; MANDELLI, F.; MARODIN, G.A.B.; BERGAMASCHI, H.; CARDOSO, L.S. Potencial produtivo de videiras cultivadas sob cobertura de plástico. Pesquisa Agropecuária Brasileira, v.44, p.141-147, 2009.

CHAVARRIA, G.;SANTOS,H.P.dos;SÔNEGO,O.R.;MARODIN, G.A.B.; BERGAMASCHI, H.; CARDOSO, L.S. Incidência de doenças e necessidade de controle em cultivo protegido de videira. Revista Brasileira de Fruticultura, v.29, 477-482, 2007.

CZERMAINSKI, A.B.C.; SÔNEGO, O.R. Influência das condições climáticas sobre a eficácia de fungicidas empregados para o controle de míldio em Vitis vinifera. Ciência Rural, v.34, p.5-11, 2004.

FERREIRA, D.F. SISVAR: um programa para análises e ensino de estatística. Revista Symposium, v.6, p.36-41, 2008.

LAFON, R.; CLERJEAU, M. Downy mildew. In: PEARSON, R.C.; GOHEEN, A.C. (Ed.). Compendium of grape diseases. Saint Paul: American Phytopathological Society, 1988. p.11-13.

LULU, J.; CASTRO, J.V. de; PEDRO JÚNIOR, M.J. Efeito do microclima na qualidade da uva de mesa 'Romana' (A 1105) cultivada sob cobertura plástica. Revista Brasileira de Fruticultura, v.27, p.422-425, 2005.

NAVES, R. de L; TESSMANN, D.J.; GARRIDO, L. da R.; SÔNEGO, R.O. Sistema de produção de uva de mesa no Norte do Paraná: doenças e seu controle. Bento Gonçalves: Embrapa Uva e Vinho, 2005. (Embrapa Uva e Vinho. Sistemas de produção, 10). Disponível em: <http://sistemasdeproducao.cnptia.embrapa. br/FontesHTML/Uva/MesaNorteParana/doencas.htm>. Acesso em: 29 jul. 2010.

NOVELLO, V.; PALMA, D. de. Growing grapes under cover. Acta Horticulturae, v.785, p.353-362, 2008

PEREIRA, V.F.; RESENDE, M.L.V. de; MONTEIRO, A.C.A.; RIBEIRO JÚNIOR, P.M.; REGINA, M. de A.; MEDEIROS, F.C.L. Produtos alternativos na proteção da videira contra o míldio. Pesquisa Agropecuária Brasileira, v.45, p.25-31, 2010.

PERUCH, L.A.M.; DELLA BRUNA, E. Relação entre doses de calda bordalesa e de fosfito potássico na intensidade do míldio e na produtividade da videira cv. 'Goethe'. Ciência Rural, v.38, p.2413-2418, 2008.

PERUCH, L.A.M.; MEDEIROS, A.M. de; BRUNA, E.D; STADINIK, M. Biomassa cítrica, extrato de algas, calda bordalesa e fosfitos no controle do míldio da videira, cv. Niágara Branca. Revista de Ciências Agroveterinárias, v.6, p.143-148, 2007.

SAS INSTITUTE. SAS user's guide: statistics. Versão 8.2. Cary: SAS Institute, 2001. 1028p.

Recebido em 5 de agosto de 2010 e aprovado em 10 de novembro de 2010 